\title{
Novel Divinyl Sulfides: Potential Luminescent Compounds
}

\author{
Matias Monçalves, Mariana M. Bassaco, Marcos A. Villetti and Claudio C. Silveira* \\ Department of Chemistry, Universidade Federal de Santa Maria, 97105.900, Santa Maria, Brazil. \\ *silveira@quimica.ufsm.br
}

Keywords: Wittig-Horner, Divinyl Sulfides, Fluorescence

\section{INTRODUCTION}

Luminescent devices based on organic compounds with low molecular weight have attracted much attention because of their application as lightemitting diodes (LED's) and flat-panel displays ${ }^{1}$. Many organic $\pi$-conjugated materials have been studied due their excellent electronic properties ${ }^{2}$ and the vinylic chalcogenides appear as an interesting class. Here we describe the preparation of novel divinyl sulfides with peripheral arylamines and a brief study of luminescent properties of these compounds.

\section{RESULTS AND DISCUSSION}

Recently, we describe the Wittig-Horner reaction of (diphenylphosphinoyl)methyl chalcogenides with aldehydes and ketones yielding symmetric and unsymmetric vinyl chalcogenides ${ }^{3}$. In this work, we performed the reaction of bis(diphenylphosphinoyl) methyl sulfide with arylamine aldehydes to obtain divinyl sulfides.

The starting aldehydes were obtained according the Scheme 1.
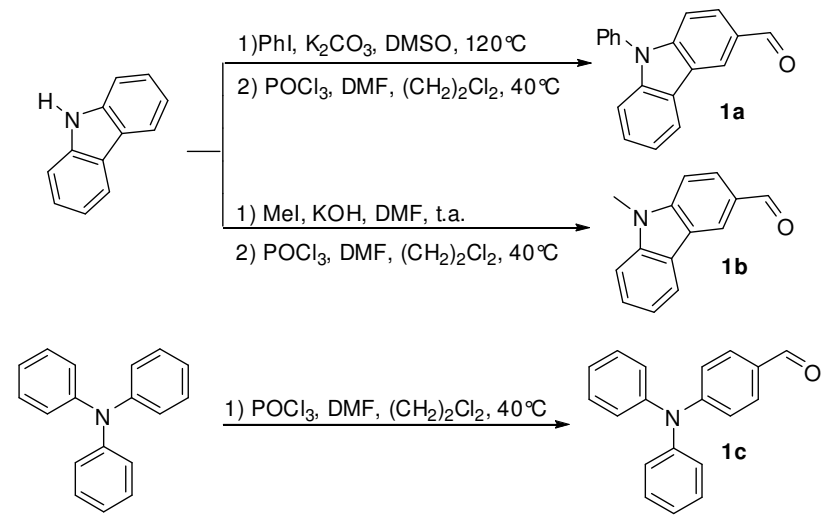

Scheme 1. Synthesis of aldehydes 1a-c.

From these aldehydes was possible to obtain the corresponding vinylic sulfides, as shown in Scheme 2.

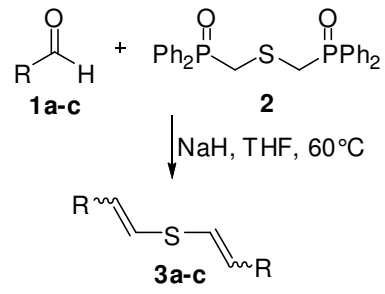

Scheme 2. Synthesis of divinyl sulfides by Wittig-Horner reaction.

$14^{\text {th }}$ Brazilian Meeting on Organic Synthesis $-14^{\text {th }}$ BMOS - September 01-05, 2011-Brasilia, Brazil
We have synthesized three new examples of divinyl sulfides, with yields between $70-75 \%$ (Figure 1). The compounds were characterized by ${ }^{1} \mathrm{H}-\mathrm{NMR},{ }^{13} \mathrm{C}$ NMR and Mass spectrometry (MS).

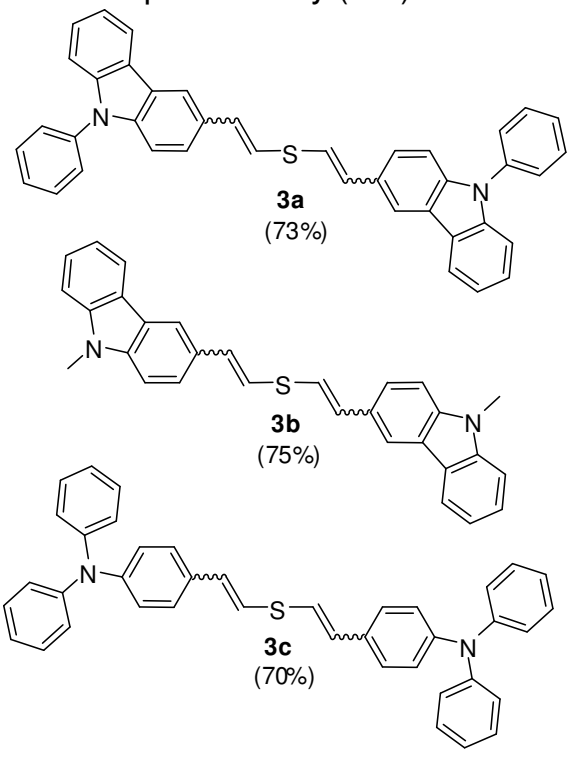

Figure 1. Divinyl sulfides 3a-c.

The study of photoluminescence in $\mathrm{CH}_{2} \mathrm{Cl}_{2}$ solution was performed for the three compounds, resulting in a maximum excitation at $279 \mathrm{~nm}$ and emission maximum at $431 \mathrm{~nm}$.

\section{CONCLUSION}

The Wittig-Horner reaction of arylamine aldehydes with bis(diphenylphosphinoyl)methyl sulfide provides new divinyl sulfides in good yield and high blue fluorescence in solution.

\section{ACKNOWLEDGEMENTS}

UFSM, CAPES, FAPERGS/PRONEX 10/0005-1 and CNPQ.

\section{REFERENCES}

${ }^{1}$ Thomas, K.; Lin, J.; Ko, C-W. J. Am. Chem. Soc. 2001, $123,9404$.

${ }^{2}$ Adhikari, R.; Neckers, D.; Shah, B. Eur. J. Org. Chem. 2009, 3341.

3 (a)Silveira, C. C.; Rinaldi, F.; Guadagnin, R. Eur. J. Org. Chem. 2007 4935; (b) Silveira, C. C.; Rinaldi, F.; Bassaco, M. M.; Guadagnin, R. C.;

Kaufman, T. S. Synthesis. 2011, 1233. 